\title{
L-Malate Reverses Oxidative Stress and Antioxidative Defenses in Liver and Heart of Aged Rats
}

\author{
J.-L. WU ${ }^{1,2,4}$, Q.-P. WU' ${ }^{2}$ X.-F. YANG ${ }^{3}$, M.-K. WEI ${ }^{2}$, J.-M. ZHANG ${ }^{2}$, Q. HUANG ${ }^{3}$, \\ X.-Y. ZHOU ${ }^{2}$
}

${ }^{1}$ South China Sea Institute of Oceanology, Chinese Academy of Sciences, Guangzhou, ${ }^{2}$ Guangdong Institute of Microbiology, Guangzhou, ${ }^{3}$ Department of Toxicology of the Center for Disease Control and Prevention of Guangdong Province, Guangzhou and ${ }^{4}$ Graduate University of Chinese Academy of Sciences, Beijing, China

Received November 20, 2006

Accepted January 29, 2007

On-line available February 8, 2007

\begin{abstract}
Summary
The intracellular levels of antioxidant and free radical scavenging enzymes are gradually altered during the aging process. An agedependent increase of oxidative stress occurring throughout the lifetime is hypothesized to be the major cause of aging. The current study examined the effects of L-malate on oxidative stress and antioxidative defenses in the liver and heart of aged rats. Sprague-Dawley male rats were randomly divided into four groups, each group consisting of 6 animals. Group la and Group IIa were young and aged control rats. Group Ib and Group IIb were young and aged rats treated with L-malate $(210 \mathrm{mg} / \mathrm{kg}$ body weight per day). L-malate was orally administrated via intragastric canula for 30 days, then the rats were sacrificed and the liver and heart were removed to determine the oxidant production, lipid peroxidation and antioxidative defenses of young and aged rats. Dietary L-malate reduced the accumulation of reactive oxygen species (ROS) and significantly decreased the level of lipid peroxidation in the liver and heart of the aged rats. Accordingly, L-malate was found to enhance the antioxidative defense system with an increased activity of antioxidant enzymes, such as superoxide dismutase (SOD) and glutathione peroxidase (GPx) and increased glutathione (GSH) levels in the liver of aged rats, a phenomenon not observed in the heart of aged rats. Our data indicate that oxidative stress was reversed and the antioxidative defense system was strengthened by dietary supplementation with L-malate.
\end{abstract}

\section{Key words}

Antioxidative defense system $\bullet$ Glutathione peroxidase $\bullet$ L-malate - Mitochondria • Reactive oxygen species

\section{Corresponding author}

Q.-P. Wu, Guangdong Institute of Microbiology, Guangzhou 510070, China. Fax: 86-20-8768-0942. E-mail: wuqp@gdas.ac.cn, microwjl@yahoo.com

\section{Introduction}

Reactive oxygen species (ROS) generated by the electron transport chain (ETC) play a pivotal role in accelerating oxidative stress in biological systems (Kohl et al. 1995, Acharya et al. 2004). Physiological amounts of ROS are a cellular requirement (Hensley et al. 2000). However, ROS are not completely detoxified and therefore, have the potential to damage lipids, protein and DNA (Harman 1993). It is generally agreed that these intracellular damages are the major cause of aging. Normally, the cell is protected by virtue of an intricate antioxidative system, consisting of enzymatic and non-enzymatic systems, to maintain redox status homeostasis. Enzymic superoxide dismutase (SOD) and glutathione peroxidase (GPx) and non-enzymic reduced glutathione (GSH) play important roles during the process by scavenging reactive oxygen species (ROS) or preventing their formation (Kabuto et al. 2003, Veerappan et al. 2004). However, the intracellular levels of antioxidant and free radical scavenging enzymes are gradually altered during the aging process (Machado et al. 1991, Semsei et al. 1991). These complex factors lead to an age-dependent increase in the fraction of oxidants that may escape quenching by a defense mechanism and cause oxidative damage to various biomolecules in the tissue. Thus, it is conceivable that dietary interventions with antioxidants, which could augment endogenous antioxidant compounds by preventing the formation or quenching 
the higher levels of oxidants, could provide an effective means of improving the antioxidative defense system with age.

L-malate plays a central role in fostering the transport of cytosolic reduced nicotinamide adenine dinucleotide (NADH) into mitochondria. It is also important as a trigger for oxidation of acetyl-CoA and $\beta$-oxidation of fatty acid by virtue of its ability to form ATP (Witter et al. 1953, Masoro and Felts 1958). Earlier studies in our laboratory have shown that supplementation of L-malate could improve physical stamina and enhance the activity of the malate-aspartate shuttle and energy metabolism (Wu et al. 2007). Maybe, the increase in metabolic activity could bring about increased oxidative stress due to increased generation of free radicals. The relationship between oxygen consumption and ROS generation is a complex and fundamental question regarding the relationship between the overall metabolic rate and the production of ROS which still remains unclear (Balaban et al. 2005). Moreover, studies on the antioxidant effect of L-malate on aging are relatively scarce and are yet to be elucidated (Romanovich and Basieva 1975). Therefore, the aim of the present study was designed to evaluate the effect of L-malate supplementation on the status of oxidant production, lipid peroxidation levels and enzymatic and non-enzymatic antioxidants in the liver and heart of aged rats.

\section{Materials and Methods}

\section{Preparation of chemicals}

L-malate, enzymes, bovine serum albumin and all substrates were purchased from Sigma Chemical Company (St. Louis, MO, USA). Dichlorodihydrofluorescein diacetate $\left(\mathrm{H}_{2}\right.$ DCF-DA) was purchased from Molecular Probes (Guangdong, China). All other chemicals used were of analytical grade and obtained from Guangdong HuanKai Microbial Sci. \& Tech. Co., Ltd., China.

\section{Animal preparation}

Male Sprague-Dawley rats (SPF grade) were used in this study. They were healthy animals maintained and housed in large spacious cages and given food and water ad libitum. The animal room was well ventilated with a $12 \mathrm{~h}$ light: $12 \mathrm{~h}$ dark cycle and maintained at 21$23{ }^{\circ} \mathrm{C}$, throughout the experimental period.

\section{Grouping of animals}

The animals were divided into two major groups - group I: young rats (3-4 months old weighing about 180-220 g), group II: aged rats (above 24 months old weighing approximately $480-560 \mathrm{~g}$ ). These groups were further subdivided into controls (Groups Ia, IIa) and experimental rats treated with L-malate (Groups Ib, IIb). Group Ia: young control rats, group IIa: aged control rats, group Ib: young treated rats, group IIb: aged treated rats. Each group consisted of 6 animals. L-malate $(210 \mathrm{mg} / \mathrm{kg}$ body weight per day) was administered via intragastric canula for 30 days. Control animals received physiological saline alone.

\section{Cell isolation and tissue homogenate preparation}

On completion of the experimental period, animals were killed by decapitation. The liver and heart samples were quickly dissected, rinsed with ice-cold physiological saline and dried by blotting between two pieces of filter paper. An accurately weighed piece of liver and heart were dispersed into single cells by collagenase perfusion (Moldeus et al. 1978, Clark et al. 1978).

Another accurately weighed piece of liver and heart was minced and homogenized in nine volumes of MSE solution (220 mM mannitol, $70 \mathrm{mM}$ sucrose, $5 \mathrm{mM}$ potassium Hepes and 2 mM EDTA buffer, $\mathrm{pH}$ 7.4), using a Teflon pestle connected to a Braun homogenizer to yield a $10 \%(\mathrm{w} / \mathrm{v})$ tissue homogenate. The homogenate was centrifuged at $1200 \times \mathrm{g}$ at $4{ }^{\circ} \mathrm{C}$ for $10 \mathrm{~min}$ (Eppendorf centrifuge 5804R, Germany) and the pellet of nuclei and cell debris was discarded. This was repeated twice and the supernatant was stored at $-80{ }^{\circ} \mathrm{C}$. The protein concentration was determined by the method of Bradford (1976) with bovine serum albumin as the standard.

\section{Determination of oxidant production}

Generation of ROS was evaluated by using DCFH fluorescent probe according to Schuessel et al. (2006) with some modifications. $\mathrm{H}_{2}$ DCF-DA is hydrolyzed and oxidized by various ROS to the fluorescent DCF (Hempel et al. 1999). $\mathrm{H}_{2}$ DCF-DA does not stain mitochondria (Diaz et al. 2003), but is oxidized mainly by peroxides in the cytosol (Walrand et al. 2003). The oxidized forms of $\mathrm{H}_{2}$ DCF-DA, DCF, could be excited with a $485 \mathrm{~nm}$ laser and emission at $530 \mathrm{~nm}$ laser of the Becton-Dickinson (BD Biosciences, San Jose, USA) FACSCalibur flow cytometer.

The $\mathrm{H}_{2}$ DCF-DA was used at a final 
concentration of $20 \mu \mathrm{M}$ by adding $20 \mu \mathrm{l}$ of $\mathrm{H}_{2}$ DCF-DA solution to $1.0 \mathrm{ml}$ cells suspension. The cells were incubated in the dark at $37{ }^{\circ} \mathrm{C}$ for $30 \mathrm{~min}$. Then, the cells were washed twice with PBS (150 g, $5 \mathrm{~min})$ and resuspended in PBS solution at $1 \times 10^{6}$ cells $/ \mathrm{ml}$ for flow cytometric analysis with Becton-Dickinson FACSCalibur utilizing CellQuest Pro software. A minimum of 8000 events were recorded per single measurement. Background fluorescence was corrected by the inclusion of parallel blanks. The level of ROS was expressed in arbitrary units (fluorescent intensity, FI). Cells were analyzed immediately after staining and always kept on ice in the dark until measurement.

\section{Determination of lipid peroxidation (LPO)}

The concentrations of homogenate LPO were determined by estimating malondialdehyde (MDA) using the thiobarbituric acid test (Ohkawa et al. 1979). To tissue homogenate $(100 \mu \mathrm{l}), 50 \mu \mathrm{l} 8.1 \%$ SDS and $20 \mu \mathrm{l}$ butylated hydroxytoluene $(0.02 \%$ in $95 \%$ ethanol, w/v) were added. The samples were vortexed and incubated at room temperature for $10 \mathrm{~min}$. Subsequently, $375 \mu 120 \%$ acetic acid ( $\mathrm{pH} 3.5)$ and $375 \mu$ thiobarbituric acid $(0.8 \%$ in $0.05 \mathrm{M} \mathrm{NaOH}$ ) were added to the mixture, vortexed and heated at $95{ }^{\circ} \mathrm{C}$ for $60 \mathrm{~min}$. The samples were then cooled immediately under running tap water and centrifuged at $3500 \mathrm{x} g$ for $10 \mathrm{~min}$. A blank was also run simultaneously and tetramethoxy propane was used as an external standard. The absorbance of the clear supernatant was determined at $532 \mathrm{~nm}$. The extent of lipid peroxidation was expressed as nmol of MDA formed per mg of protein.

\section{Determination of glutathione peroxidase activity}

The activity of glutathione peroxidase (GPx; EC 1.6.4.2) was estimated by the method of Sazuke et al. (1989) with slight modifications. Briefly, homogenates mixed with GSH and $\mathrm{H}_{2} \mathrm{O}_{2}$ were incubated at $37{ }^{\circ} \mathrm{C}$ for $5 \mathrm{~min}$, that was followed by the addition $10 \%$ trichloracetric acid (TCA). After the samples had been centrifuged at $3500 \times \mathrm{g}$ for $10 \mathrm{~min}$, the supernatant was collected and mixed with disodium hydrogen phosphate and 5, 5'-dithio-bis-2-nitrobenzoic acid (DTNB). The absorbance of the samples was recorded against the blank at $412 \mathrm{~nm}$. The unit of activity was expressed as $\mu \mathrm{mol}$ GSH oxidation per min per mg protein.

\section{Determination of superoxide dismutase activity} Total $(\mathrm{Cu}-\mathrm{Zn}$ and $\mathrm{Mn})$ superoxide dismutase
(SOD; EC 1.15.1.1) activity was determined according to the method of Sun et al. (1988) with a slight modification by Durak et al. (1993). The principle of the method is based on the inhibition of nitroblue tetrazolium (NBT) reduction by the xanthine-xanthine oxidase system as a superoxide generator. Activity was assessed in the ethanol phase of the supernatant after a $1.0 \mathrm{ml}$ ethanol/chloroform mixture $(5 / 3, \mathrm{v} / \mathrm{v})$ was added to the same volume of a sample and centrifuged. One unit of SOD was defined as the amount of enzyme causing $50 \%$ inhibition in the NBT reduction rate. Activity was expressed as units per mg protein.

\section{Determination of glutathione}

The GSH level of homogenate was measured at $412 \mathrm{~nm}$ according to Moron et al. (1979) with a slight modification. Briefly, the protein in samples was precipitated with $50 \%$ TCA and then centrifuged at 1000 $\mathrm{x} g$ for $5 \mathrm{~min}$. The reaction mixture contained $0.5 \mathrm{ml}$ of supernatant, $2.0 \mathrm{ml}$ of $0.2 \mathrm{M}$ Tris-EDTA buffer ( $\mathrm{pH} 8.9$ ) and $0.1 \mathrm{ml}$ of $0.01 \mathrm{M}$ DTNB. The solution was kept at room temperature for $5 \mathrm{~min}$, and then read against the blank at $412 \mathrm{~nm}$ on the spectrophotometer. The GSH concentration was calculated from a standard curve.

\section{Statistical analysis}

The original data were evaluated with SPSS software. All results were presented as mean \pm S.D. Oneway analysis variance (ANOVA) was used for statistical analysis, and all tests were considered to be statistically significant at $\mathrm{P}<0.05$.

\section{Results}

\section{Effect of L-malate on oxidant production}

Figure 1 represents the level of ROS in the liver and heart of young and aged rats. For this experiment we used a redox-sensitive dye $\mathrm{H}_{2}$ DCF-DA, which is fluorescent upon oxidation. The level of ROS was found to be enhanced $43.5 \%(\mathrm{P}<0.05)$ in the liver of aged control rats (Group IIa) than in that of young control rats. Similarly, the level of ROS was found to be increased $84.3 \%(\mathrm{P}<0.01)$ in the heart of aged control rats. Lmalate significantly reduced the level of ROS generation in the liver and heart of aged treated rats $(\mathrm{P}<0.01)$. There was no significant effect on young rats.

\section{Effect of L-malate on lipid peroxidation}

To assess whether L-malate modulated age- 


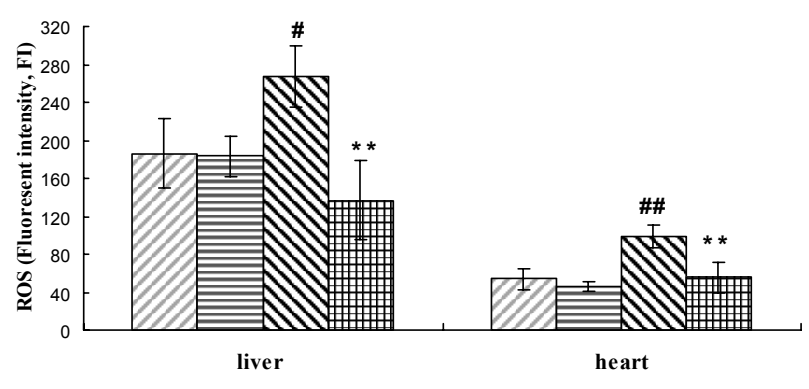

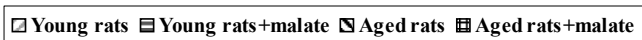

Fig. 1. Effect of L-malate on oxidant production in liver and heart of young and aged rats. Values are the means \pm S.D. $(n=4)$. ROS level was expressed in arbitrary units (fluorescent intensity, FI). ${ }^{\#} \mathrm{P}<0.05$ and ${ }^{\# \#} \mathrm{P}<0.01$ indicates significant difference compared with young rats (Group Ia); $* \mathrm{P}<0.05$ and $* * \mathrm{P}<0.01$ indicates significant difference compared with aged rats (Group IIa).

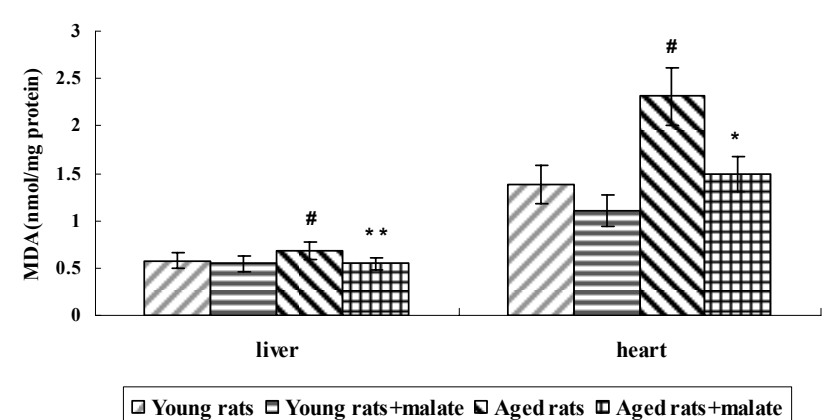

Fig. 2. Effect of L-malate on level of lipid peroxidation in liver and heart of young and aged rats. Values are the means \pm S.D. $(n=6) .{ }^{\#} P<0.05$ and ${ }^{\# \#} P<0.01$ indicates significant difference compared with young rats (Group Ia); $* \mathrm{P}<0.05$ and $* * \mathrm{P}<0.01$ indicates significant difference compared with aged rats (Group IIa).

related oxidative stress, we measured steady-state levels of MDA, a marker of lipid peroxidation. Figure 2 shows the lipid peroxidation status in the liver and heart tissue homogenate of young and aged rats without or with supplementation of L-malate. Lipid peroxidation was found to be increased by $18.7 \%$ and $67.4 \%$ in the liver and heart, respectively, of aged control rats compared with young controls. Administration of L-malate significantly decreased the lipid peroxidation in the liver and heart of aged treated rats. There was no significant difference between young treated rats and young control rats.

\section{Effect of L-malate on antioxidative defenses}

The effects of L-malate supplementation on antioxidative defense were examined in the liver and heart of young and aged rats. Figures 3 and 4 show the antioxidant enzyme activities of GPx and SOD in the liver and heart of control and L-malate treated rats. The

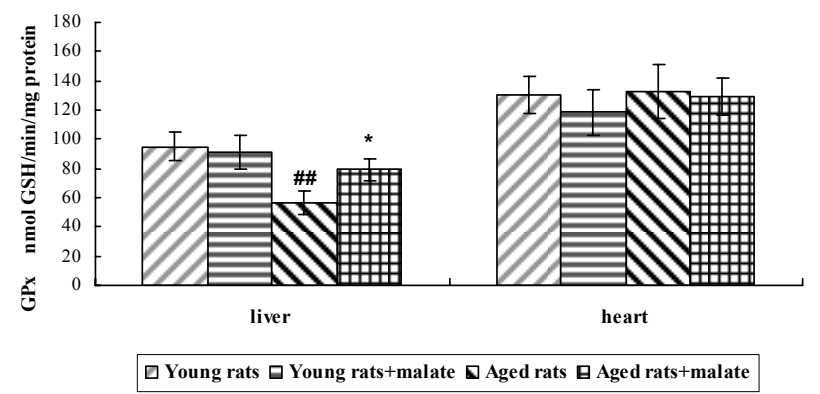

Fig. 3. Effect of L-malate on GPx activity in liver and heart of young and aged rats. Values are the means \pm S.D. $(n=6)$. ${ }^{\#} P<0.05$ and ${ }^{\# \#} P<0.01$ indicates significant difference compared with young rats (Group la); $* \mathrm{P}<0.05$ and $* * \mathrm{P}<0.01$ indicates significant difference compared with aged rats (Group IIa).

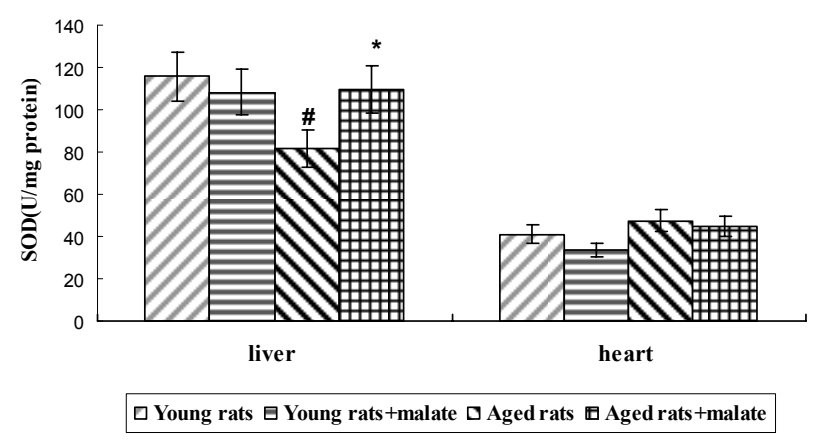

Fig. 4. Effect of L-malate on SOD activity in liver and heart of young and aged rats. Values are the means \pm S.D. $(n=6)$. ${ }^{\#} P<0.05$ and ${ }^{\# \#} P<0.01$ indicates significant difference compared with young rats (Group la); $* \mathrm{P}<0.05$ and $* * \mathrm{P}<0.01$ indicates significant difference compared with aged rats (Group IIa).

activities of these antioxidant enzymes were found to be significantly lower in the liver of aged control rats compared with young controls. The activity of GPx and SOD in the liver was decreased by $40.5 \%$ and $29.5 \%$, respectively, in aged controls. L-malate administration was found to enhance $(\mathrm{P}<0.05)$ the activities of these enzymes by $39.9 \%$ and $34.4 \%$ in GPx activity and SOD activity, respectively, in the liver during aging. However, L-malate had no effect on activities of both enzymes in the heart.

The levels of GSH in the liver and heart were measured to determine whether these low molecular weight antioxidants declined with age. The level of GSH in the liver was lower $(\mathrm{P}<0.05)$ in aged control rats compared with young controls (Fig. 5). L-malate administration increased $(\mathrm{P}<0.01)$ the level of GSH in the liver of aged rats increased by $68.1 \%$. The level of GSH in the heart of aged control rats was also higher $(\mathrm{P}<0.05)$. L-malate had no effects on the level of GSH in the heart of young and aged rats. 




Fig. 5. Effect of L-malate on GSH in liver and heart of young and aged rats. Values are the means \pm S.D. $(n=6) .{ }^{\#} P<0.05$ and \#\# $P<0.01$ indicates significant difference compared with young rats (Group la); $* \mathrm{P}<0.05$ and $* * P<0.01$ indicates significant difference compared with aged rats (Group IIa).

\section{Discussion}

The crucial role of L-malate in cellular metabolism is to control the influx of NADH into mitochondria for oxidative phosphorylation and subsequent energy production. However, its role as an antioxidant in the aging process is not yet elucidated. The present investigation thus focused on the effects of L-malate on oxidative stress and antioxidant status in the liver and heart of aged rats. The liver and heart were chosen as model systems for the evaluation of L-malate effects on oxidative stress and antioxidant defense system since these tissues were particularly prone to oxidative damage and the malate-aspartate shuttle was the dominant shuttle in these two organs (Scholz et al. 2000).

Age-associated reductions in the activities of antioxidant enzymes related to increases in oxidant production and LPO, which were found in the current study, are in agreement with previous findings (Kalaiselvi and Panneerselvam 1998, Hagen et al. 2002). The $\mathrm{H}_{2}$ DCF-DA assay has been adapted to measure oxidant production in various tissue cells (Bejma et al. 2000, Schuessel et al. 2006, Sethumadhavan and Chinnakannu 2006). A progressive increase in the production of ROS with aging has been correlated with a decrease in the number of functional mitochondria per cell, as well as with a decline in the production of ATP, protein synthesis and increase in peroxide leakage (Herbener 1976, Vorbeck et al. 1982, Sandhu and Kaur 2003). The main findings of our study were that supplementation of L-malate decreased $\mathrm{H}_{2}$ DCF-DA oxidation in the liver and heart of aged rats. The decrease of ROS levels may be attributed either to their reduced generation or to the enhancement in antioxidant levels. Previous reports showed that the electron transport efficiency decreased in aged rats (Kumaran et al. 2004). The loss of electron transport efficacy has the additional detrimental effect of increasing the production of intracellular ROS and enhancing oxidative damage (Buttgereit and Brand 1995). Recently, Speakman et al. (2004) have suggested that proton leakage and augmented basal metabolism may protect against ROS production and aging. Early studies in our laboratory have shown that supplementation of L-malate enhances the activity of malate-aspartate shuttle and energy metabolism ( $\mathrm{Wu}$ et al. 2007). It can be assumed that L-malate could reduce the generation of ROS by increasing the efficiency of electron transport and thus enhancing the activity of energy metabolism.

Lipid peroxidation is used as an index for measuring the damage that occurs in cell membranes as a result of free radical insult (Husain et al. 2001). The degree of LPO has been assessed on the basis of MDA formation, which has been routinely used as an index of LPO. Similar to other studies (Hagen et al. 1999, 2002, Kalaiselvi and Panneerselvam 1998), age-associated increase in LPO was observed in our study. Lipids act as vital substrates for LPO, and the enhancement of lipid profile during aging (Leoper et al. 1983) may be the cause for increased LPO. The data of the present study showed that L-malate administration decreased LPO in liver and heart of aged rats. It is possible that L-malate decreases the level of lipids in aged treated rats by enhancing metabolic rates and $\beta$-oxidation, thereby lowering the availability of lipids for peroxidation.

The age-related increase in LPO might be a reflection of decreased enzymatic and non-enzymatic antioxidant protection (Yu 1994). GPx and SOD are the main enzymes of the antioxidant defense system. A significant decline in the levels of these enzymes in the liver of aged rats observed in our study is in accordance with extensive studies (Kalaiselvi and Panneerselvam 1998, Bejma et al. 2000, Kumaran et al. 2004, Savitha et al. 2005). We found no changes in the activities of these enzymes in the heart during aging, although previous studies showed a decrease (Kumaran et al. 2004, Savitha et al. 2005). Such a difference between results may be caused by different experimental conditions. After treatment with L-malate, the aged rats were found to regain SOD activity in the liver to a significant level. The reason of the increased SOD activity could be the providing the redox status of L-malate. GPx is a selenium-containing antioxidant enzyme, which effectively reduces hydrogen peroxide and lipid 
peroxides to water and lipid alcohols, respectively, at the expense of reduced glutathione. The decreased GPx activity in the liver of aged rats may be due to the decline of glutathione concentration. L-malate supplementation enhanced the level of glutathione in aged rats in the present study and the increased level of the substrate glutathione may be responsible for the increase in the activity of GPx in the liver of aged treated rats. Furthermore, an other possible reason could be the increased synthesis of GPx and SOD. The reduced protein synthesis during aging attributed to decreased ATP production (Nair 2005) may be the cause for the reduction in the activities of these enzymes. L-malate supplementation by virtue of its ability to enhance ATP production (Bendahan et al. 2002) might have improved the overall protein synthesis in cells. This may also explain why we observed a beneficial effect of L-malate only in old but not in young rats.

As a water-soluble tripeptide, glutathione is the most abundant intracellular small thiol molecule and a predominant defense against ROS in tissues. GSH reacts directly with ROS and electrophilic metabolites, protects essential thiol groups from oxidation, promotes the regeneration of $\alpha$-tocopherol, and serves as a substrate for GSH-related enzymes, e.g. GPx and glutathione S-transferases (Townsend et al. 2003). GSH plays an important role in the maintenance of the intracellular redox state and in the cellular defense against oxidative damage. Our finding that the level of GSH is decreased in the liver of aged rats is consistent with previous reports (Kalaiselvi and Panneerselvam 1998, Mosoni et al. 2004). The observed decrease in glutathione concentration in the liver of aged rats may be caused by the excessive oxidative damage due to free radicals. The decline in the levels of GSH seen in livers of aged rats was completely reversed with supplementation of L-malate. The recycling of GSH from GSSG (oxidized glutathione) is catalyzed by the enzyme glutathione reductase using NADPH as a cofactor. L-malate increases the TCA metabolism which in turn increases NADPH generation (Bobyleva-Guarriero 1986). Therefore, the observed increase in GSH after treatment could be ascribed to the ability of L-malate to increase TCA metabolism. Our results showing, that levels of GSH were increased in the heart of aged rats, confirm previous findings (Fiebig et al. 1996), but the levels of GSH in the heart were unaffected by L-malate treatment. A possible mechanism may be that antioxidants in the heart of aged rats have a considerable adaptability to respond to prooxidant exposure (Ji et al. 1998).

In conclusion, our study indicates that the supplementation of L-malate may considerably reduce oxidative stress in the liver and heart of aged rats by alleviating LPO through scavenging of ROS and increasing the antioxidative defenses in the liver of aged rats which then detoxify free radicals. Although our present findings suggest that L-malate supplementation may be a safe mean of increasing protection against oxidative damage, long-term feeding studies with L-malate are needed to determine whether benefits of L-malate seen in aged animals can be sustained over the time.

\section{Conflict of Interest}

There is no conflict of interest.

\section{Acknowledgements}

We express our thanks to Rui-Yi Chen and Jian-Bing Tan for their excellent technical help and Yun-Ping Peng for her critical comments. This study was supported by grants from the Ministry of Major Science \& Technology of Guangzhou (2004Z-E0061), Science \& Technology of Guangdong Province (2004B40101011) and Special and Focal Foundation in Medical Science of Guangdong Province (Yue Wei [2003] 246).

\section{References}

ACHARYA UR, MISHRA M, MISHRA I: Status of antioxidant defense system in chromium-induced Swiss mice tissues. Environ Toxicol Pharmacol 17: 117-123, 2004.

BALABAN RS, NEMOTO S, FINKEL T: Mitochondria, oxidants and aging. Cell 120: 483-495, 2005.

BEJMA J, RAMIRES P, JI LL: Free radical generation and oxidative stress with ageing and exercise: differential effects in the myocardium and liver. Acta Physiol Scand 169: 343-351, 2000.

BENDAHAN D, MATTEI JP, GHATTAS B, CONFORT-GOUNY S, LE GUERN ME, COZZONE PJ: Citrulline/malate promotes aerobic energy production in human exercising muscle. Br J Sports Med 36: 282289, 2002. 
BOBYLEVA-GUARRIERO V, WEHBIE TS, LARDY HA: The role of malate in hormone-induced enhancement of mitochondirial respiration. Arch Biochem Biophys 245: 477-482, 1986.

BRADFORD MM: A rapid and sensitive method for the quantization of microgram quantities of protein utilizing the principle of protein-dye binding. Anal Biochem 72: 248-254, 1976.

BUTTGEREIT F, BRAND MD: A hierarchy of ATP-consuming processes in mammalian cells. Biochem J 312: 163$167,1995$.

CLARK MG, GANNON BJ, BODKIN N, PATTEN GS, BERRY MN: An improved procedure for the high yield preparation of intact beating heart cells from the adult rat biochemical and morphological study. $J$ Mol Cell Cardiol 10: 1101-1121, 1978.

DIAZ G, LIU S, ISOLA R, DIANA A, FALCHI AM: Mitochondrial localization of reactive oxygen species by dihydrofluorescein probes. Histochem Cell Biol 120: 319-325, 2003.

DURAK I, YURTARSLANI Z, CANBOLAT O, AKYOL O: A methodological approach to superoxide dismutase (SOD) activity assay based on inhibition of nitroblue tetrazolium (NBT) reduction. Clin Chim Acta 31: 103104, 1993.

FIEBIG R, LEEUWENBURGH C, GORE M, JI LL: The interactive effects of aging and training on myocardial antioxidant enzymes and oxidative stress. Age 19: 83-89, 1996.

HAGEN TM, INGERSOLL RT, LYKKESFELDT J, LIU J, WEHR CM, VINARSKY V, BARTHOLOMEW JC, AMES AB: (R)-alpha-lipoic acid-supplemented old rats have improved mitochondrial function, decreased oxidative damage, and increased metabolic rate. FASEB J 13: 411-418, 1999.

HAGEN TM, LIU J, LYKKESFELDT J, WEHR CM, INGERSOLL RT, VINARSKY V, BARTHOLOMEW JC, AMES BN: Feeding acetyl-L-carnitine and lipoic acid to old rats significantly improves metabolic function while decreasing oxidative stress. Proc Natl Acad Sci USA 99: 1870-1875, 2002.

HARMAN D: Free radical involvement in ageing. Pathophysiology and therapeutic implications. Drugs Aging 3: 60-80, 1993.

HEMPEL SL, BUETTNER GR, O'MALLEY YQ, WESSELS DA, FLAHERTY DM: Dihydrofluorescein diacetate is superior for detecting intracellular oxidants: comparison with $2^{\prime}, 7^{\prime}$-dichlorodihydrofluorescein diacetate, 5 (and 6)-carboxy-2',7'-dichlorodihydrofluorescein diacetate, and dihydrorhodamine 123. Free Radic Biol Med 27: 146-159, 1999.

HENSLEY K, ROBINSON KA, GABBITA SP, SALSMAN S, FLOYD RA: Reactive oxygen species, cell signaling, and cell injury. Free Radic Biol Med 28: 1456-1462, 2000.

HERBENER GH: A morphometric study of age-dependent changes in mitochondrial population of mouse liver and heart. $J$ Gerontol 31: 8-12, 1976.

HUSAIN K, SCOTT BR, REDDY SK, SOMANI SM: Chronic ethanol and nicotine interaction on rat tissue antioxidant defense system. Alcohol 25: 89-97, 2001.

JI LL, LEEUWENBRUGH C, LEICHTWEIS S, GORE M, FIEBIG R, HOLLANDER J, BEJMA J: Oxidative stress and aging. Role of exercise and its influences on antioxidant systems. Ann N Y Acad Sci 854: 102-117, 1998.

KABUTO H, HASUIKE S, MINAGAWA N, SHISHIBORI T: Effects of bisphenol A on the metabolisms of active oxygen species in mouse tissues. Environ Res 93: 31-35, 2003.

KALAISELVI T, PANNEERSELVAM C: Effect of L-carnitine on the status of lipid peroxidation and antioxidants in aging rats. J Nutr Biochem 9:575-581, 1998.

KOHL C, MORGAN P, GESCHER A: Metabolism of genotoxicant 2- nitropropane to a nitric oxide species. Chem Biol Interact 97: 175-184, 1995.

KUMARAN S, SUBATHRA M, BALU M, PANNEERSELVAM C: Age related decreased electron transport chain complexes in heart and skeletal muscle of aged rats: role of L-carnitine. Chem Biol Interact 148: 11-18, 2004.

LOEPER JE, EMERIT J, GOY J, BEDU O, LOEPER J: Lipid peroxidation during human atherosclerosis. IRCS Med Sci 11: 1034-1035, 1983.

MACHADO A, AYALO AA, GORDILLA E, REVILLA E, SANTA MC: Relationship between enzymatic activity loss and post translational protein modification in aging. Arch Gerontol Geriatr 12: 187-97, 1991. 
MASORO EJ, FELTS JM: Role of carbohydrate metabolism in promoting fatty acid oxidation. J Biol Chem 231: $347-$ $356,1958$.

MOLDEUS P, HOGBERG J, ORRENIUS S: Isolation and use of liver cells. Methods Enzymol 52: 60-71, 1978.

MORON MS, DEPIERRE JW, MANNERVIK B: Levels of glutathione, glutathione reductase and glutathione Stransferase activities in rat lung and liver. Biochim Biophys Acta 582: 67-78, 1979.

MOSONI L, BREUILLE D, BUFFIERE C, OBLED C, MIRAND PP: Age-related changes in glutathione availability and skeletal muscle carbonyl content in healthy rats. Exp Gerontol. 39: 203-210, 2004.

NAIR KS: Aging muscle. Am J Clin Nutr 81: 953-963, 2005.

OHKAWA H, OHISHI N, YAGI K: Assay for lipid peroxides in animal tissues by the thiobarbituric acid reaction. Anal Biochem 95: 351-358, 1979.

ROMANOVICH EA, BASIEVA FI: Effect of a malic acid load on the blood and urine content in animals of the products of a malate dehydrogenase reaction and the correlation of reduced and oxidized forms of ascorbic acid. Vopr Med Khim 21: 131-133, 1975.

SANDHU SK, KAUR G: Mitochondrial electron transport chain complexes in aging rat brain and lymphocytes. Biogerontology 4: 19-29, 2003.

SAVITHA S, TAMILSELVAN J, ANUSUYADEVI M, PANNEERSELVAM C: Oxidative stress on mitochondrial antioxidant defense system in the aging process: role of DL-alpha-lipoic acid and L-carnitine. Clin Chim Acta 355: 173-180, 2005.

SAZUKA Y, TANIZAWA H, TAKINO Y: Effect of adriamycin on the activities of superoxide dismutase, glutathione peroxidase and catalase in tissues of mice. Jpn J Cancer Res 80: 89-94, 1989.

SCHOLZ TD, TENEYCK YJ, CCHUTTE BC: Thyroid hormone regulation of the NADH shuttles in liver and cardiac mitochondria. Mol Cell Cardiol 32: 1-10, 2000.

SCHUESSEL K, FREY C, JOURDAN C, KEIL U, WEBER CC, MULLER-SPAHN F, MULLER WE, ECKERT A: Aging sensitizes toward ROS formation and lipid peroxidation in PS1M146L transgenic mice. Free Radic Biol Med 40: 850-862, 2006.

SEMSEI I, RAO G, RICHARDSON A: Expression of superoxide dismutase and catalase in rat brain as a function of age. Mech Ageing Dev 58: 13-19, 1991.

SETHUMADHAVAN S, CHINNAKANNU P: Carnitine and lipoic acid alleviates protein oxidation in heart mitochondria during aging process. Biogerontology 7: 101-109, 2006.

SPEAKMAN JR, TALBORT DA, SELMAN C, SNART S, MCLAREN JS, REDMAN P, KROL E, JACKSON DM, JOHNSON MS, BRAND MD: Uncoupled and surviving: individual mice with high metabolism have greater mitochondrial uncoupling and live longer. Aging Cell 3: 87-95, 2004.

SUN Y, OBERLEY LW, LI Y: A simple method for clinical assay of superoxide dismutase. Clin Chem 34: 497-500, 1988.

TOWNSEND DM, TEW KD, TAPIERO H: The importance of glutathione in human disease. Biomed Pharmacother 57: 145-155, 2003.

VEERAPPAN RM, SENTHIL S, RAO MR, RAVIKUMAR R, PUGALENDI KV: Redox status and lipid peroxidation in alcoholic hypertensive patients and alcoholic hypertensive patients with diabetes. Clin Chim Acta 340: $207-$ $212,2004$.

VORBECK M, MARTIN A, PARK J, TOWNSEND J: Aging related decrease in hepatic cytochrome oxidase of the Fischer 344 rat. Arch Biochem Biophys 214: 67-79, 1982.

WALRAND S, VALEIX S, RODRIGUEZ C, LIGOT P, CHASSAGNE J, VASSON MP: Flow cytometry study of polymorphonuclear neutrophil oxidative burst: a comparison of three fluorescent probes. Clin Chim Acta 331: 103-110, 2003.

WITTER RF, NEWCOMB EH, STOTZ E: The role of adenosinetriphosphate in the activation of fatty acid oxidation in vitro. J Biol Chem 200: 703-713, 1953.

WU JL, WU QP, HUANG JM, CHEN RY, CAI M, TAN JB: Effects of L-malate on physical stamina and activities of enzymes related to the malate-aspartate shuttle in liver of mice. Physiol Res 56: 213-220, 2007.

YU PB: Cellular defences against damage from reactive oxygen species. Physiol Rev 74: 134-162, 1994. 